CHAPMAN Anne, Christine BARTHE et Philippe REVOL (éds), Cap Horn 1882-1883 : rencontre avec les Indiens yaghan

\title{
Dominique Legoupil
}

\section{OpenEdition}

\section{Journals}

Édition électronique

URL : https://journals.openedition.org/jsa/1801

DOI : 10.4000/jsa.1801

ISSN : 1957-7842

Éditeur

Société des américanistes

\section{Édition imprimée}

Date de publication : 5 juin 2004

Pagination : 207

ISSN : 0037-9174

\section{Référence électronique}

Dominique Legoupil, « chapman Anne, Christine barthe et Philippe revol (éds), Cap Horn 1882-1883:

rencontre avec les Indiens yaghan ", Journal de la Société des américanistes [En ligne], 90-2 | 2004, mis en ligne le 17 novembre 2005, consulté le 04 septembre 2022. URL : http://journals.openedition.org/jsa/ 1801 ; DOI : https://doi.org/10.4000/jsa.1801

Ce document a été généré automatiquement le 4 septembre 2022

Tous droits réservés 


\title{
CHAPMAN Anne, Christine BARTHE et Philippe REVOL (éds), Cap Horn 1882-1883 : rencontre avec les Indiens yaghan
}

\author{
Dominique Legoupil
}

\section{RÉFÉRENCE}

CHAPMAN Anne, Christine BARTHE et Philippe REVOL (éds), Cap Horn 1882-1883 : rencontre avec les Indiens yaghan, Éditions La Martinière, coll. « Artémuse », Paris, 1995, 186 p., ill., photos, carte

1 Magnifiquement illustré, ce livre offre la reproduction d'une collection de photographies de la photothèque du musée de l'Homme, prises par deux officiers de la mission scientifique du Cap Horn, Payen et Doze, lors de leur séjour de près d'une année sur l'île Hoste, en face du Cap Horn. Ces photographies sur plaques de verre, les premières connues des Indiens des archipels de Terre de Feu, ont été si souvent pillées et mal reproduites à partir de leur publication originale en 1891, notamment sur le continent sud-américain, qu'on a l'impression de redécouvrir ici les plus connues et d'en découvrir d'autres moins célèbres. Elles illustrent des textes d'Anne Chapman sur certains aspects de l'histoire de l'expédition (son but dans le cadre de la première Année polaire internationale ou le détail des navigations dirigées par le commandant Martial) ou encore sur la vision qu'une indigène de l'époque pouvait avoir des Français. Ailleurs, Revol évoque le regard des Européens sur les Indiens de Patagonie à la fin du XIX ${ }^{\mathrm{e}}$ siècle et le sort des quelques « spécimens " ramenés en France; il présente également Hyades, l'un des rédacteurs, avec Deniker, du volume VII (Anthropologie-Ethnographie) de la mission scientifique du Cap Horn. De son côté, Christine Barthe présente l'histoire de la photographie d'après nature et son rôle dans la recherche ethnographique. Enfin David 
Jacquin fournit un très utile inventaire de l'ensemble de cette remarquable collection photographique.

2 Ce livre est aujourd'hui considéré comme épuisé, mais quelques exemplaires devraient être disponibles à la bibliothèque du musée de l'Homme (laquelle est en cours de transfert au musée du quai Branly).

\section{AUTEURS}

\section{DOMINIQUE LEGOUPIL}

CNRS, UMR 7041, Maison de l'archéologie et de l'ethnologie, Nanterre 